\title{
Analysis of an alternative human CD133 promoter reveals the implication of Ras/ERK pathway in tumor stem-like hallmarks
}

\author{
Kouichi Tabu ${ }^{1,2,3,4}$, Taichi Kimura ${ }^{1}$, Ken Sasai ${ }^{1,5}$, Lei Wang ${ }^{1}$, Norihisa Bizen ${ }^{2,4}$, Hiroshi Nishihara ${ }^{6}$, Tetsuya Taga ${ }^{2,3,4}$,
} Shinya Tanaka ${ }^{1,6^{*}}$

\begin{abstract}
Background: An increasing number of studies support the presence of stem-like cells in human malignancies. These cells are primarily responsible for tumor initiation and thus considered as a potential target to eradicate tumors. CD133 has been identified as an important cell surface marker to enrich the stem-like population in various human tumors. To reveal the molecular machinery underlying the stem-like features in tumor cells, we analyzed a promoter of CD133 gene using human colon carcinoma Caco-2 and synovial sarcoma Fuji cells, which endogenously express CD133 gene.
\end{abstract}

Results: A reporter analysis revealed that P5 promoter, located far upstream in a human CD133 gene locus, exhibits the highest activity among the five putative promoters (P1 to P5). Deletion and mutation analysis identified two ETS binding sites in the P5 region as being essential for its promoter activity. Electrophoretic mobility shift assays demonstrated the specific binding between nuclear factors and the ETS binding sequence. Overexpression of dominant-negative forms of Ets 2 and Elk1 resulted in the significant decrease of P5 activity. Furthermore, treatment of Fuji cells with a specific MEK/ERK inhibitor, U0126, also markedly decreased CD133 expression, but there was no significant effect in Caco-2 cells, suggesting cell type-specific regulation of CD133 expression. Instead, the side population, another hallmark of TSLCs, was dramatically diminished in Caco-2 cells by U0126. Finally, Ras-mediated oncogenic transformation in normal human astrocytes conferred the stem-like capability to form neurosphere-like colonies with the increase of CD133 mRNA expression.

Conclusions: In conclusion, the Ras/ERK pathway at least in part contributes to the maintenance and the acquisition of stem-like hallmarks, although the extent of its contribution is varied in a cell type-specific manner. These findings could help our comprehensive understanding of tumor stemness, and also improve the development of eradicative therapies against human malignancies.

\section{Background}

The tumors contain a sub-population of specific cells which are primarily involved in tumor formation and maintenance [1]. Those cells are referred as tumor stem-like cells (TSLCs), and CD133 (also known as prominin-1 or AC133) has been considered as an important marker to enrich the stem-like population in tumors of various tissues, including those of the brain [2], prostate [3], pancreas [4], liver [5], colon [6,7], and skin for

\footnotetext{
* Correspondence: tanaka@med.hokudai.ac.jp

'Laboratory of Cancer Research, Department of Pathology, Hokkaido University Graduate School of Medicine, Kita-15, Nishi-7, Kita-ku, Sapporo, Japan
}

(c) 2010 Tabu et al; licensee BioMed Central Ltd. This is an Open Access article distributed under the terms of the Creative Commons Attribution License (http://creativecommons.org/licenses/by/2.0), which permits unrestricted use, distribution, and reproduction in any medium, provided the original work is properly cited. melanoma [8]. CD133 ${ }^{+}$tumor cells possess the ability to self-renew without limit and to generate the majority of differentiated progenies [9]. They are also more resistant to chemo- and radiotherapy when compared to $\mathrm{CD} 133^{-}$ tumor cells, resulting in tumor progression and recurrence, and thus are considered as a potential therapeutic target to eradicate tumors [10-12]. However, the molecular mechanisms underlying this tumor stemness are still under investigation.

CD133 is a cellular surface glycoprotein containing five transmembrane regions and two glycosylated extracellular loops and has a molecular weight of 97-120 $\mathrm{kDa}$. It was identified as a specific antigen for human 
hematopoietic stem cells [13], and is currently used for the isolation of stem-like cells from numerous tissues [13-20]. Although little is known about the biological function of CD133, recent studies have shown that prominin-1 null mice were born and aged normally [21], but resulted in progressive degeneration of mature photoreceptors with complete loss of vision after postnatal day 15 [22]. Transcription of CD133 gene is known to be controlled by alternative five promoters (P1, P2, P3, P4, and P5), and exon 1 produces different spliced 5'-UTRs, which are expressed in a tissue-specific manner [23]. We previously showed that the methylation status of $\mathrm{CpG}$ sites residing in $\mathrm{P} 1$ and $\mathrm{P} 2$ regions is inversely correlated with the expression levels of CD133 mRNA in human glioma tissues [24]; however, any molecules involved in the transcriptional regulation of CD133 gene are still unknown.

The E26 transformation-specific (ETS) family consists of over 35 Ets genes that can be structurally categorized into 11 subfamilies in humans [25]. Individual Ets genes share a highly conserved DNA-binding domain composed of about 85 amino acid residues referred to as the ETS domain, which recognizes purine-rich GGA(A/T) (ETS binding site; EBS). Several Ets factors have been shown to be nuclear targets for the activation of the Ras/Raf/MEK/ ERK signaling pathway and are involved in various biological processes, including cell proliferation, apoptosis, differentiation, hematopoiesis, tissue remodeling, angiogenesis, metastasis, and oncogenic transformation [25]. The altered expression levels of Ets or chromosomal amplification, deletion, and translocation are known to cause human leukemia or specific types of solid tumors [26].

To investigate the molecular mechanism underlying stem-like features in human tumors, we characterized a promoter region of human CD133 gene by using human carcinoma and sarcoma cell lines. We found that the ERK pathway is involved in the expression of CD133, and its inhibition was also shown to decrease the frequency of side population (SP), another hallmark of stem-like cells. Finally, it was revealed that Ras-mediated transformed astrocytes have an ability to form greater colonies in the neural stem cell culture condition, together with the increased CD133 mRNA expression. Thus, our finding could provide important insights into the molecular basis of tumor stemness.

\section{Methods}

\section{Cell culture, reagents, and transfection}

The human colon carcinoma cell line Caco-2 and synovial sarcoma cell line Fuji were cultured in DMEM supplemented with $20 \%$ and $10 \%$ fetal bovine serum (FBS), respectively. The immortalized normal human astrocytes NHA/TS and Ras-transformed NHA/TSR cells were previously established [27]. Cells were treated with the
MEK inhibitor U0126 (Cell Signaling Technologies, Beverly, MA, USA) at $20 \mu \mathrm{M}$ for 72 hours with renewal of media every 24 hours. Fugene HD transfection reagent (Roche, Indianapolis, USA) was used for transfection. For primary neurosphere formation, NHA/TS and NHA/TSR cells $(1000$ cells $/ 3.5 \mathrm{~cm}$ dish) were cultured in neural stem cell (NSC) medium (DMEM/F12 containing $20 \mathrm{ng} / \mathrm{ml} \mathrm{EGF,} 20 \mathrm{ng} / \mathrm{ml} \mathrm{bFGF}, 1 \times \mathrm{B} 27$, and $1 \%$ penicillin and streptomycin) for 2 weeks as described previously with minor modification [28]. After 2 weeks of culture, TSR spheres were collected, enzymatically dissociated by Trypsin-EDTA and reseeded at a density of 1000 cells $/ 3.5 \mathrm{~cm}$ dish) for secondary sphere formation. For clonal culture, single NHA/TS or NHA/TSR cell was transferred into 48-well plates containing NSC medium using cell sorter. After 2 weeks, each well was manually screened for a colony using phase contrast microscopy. Thereafter, each individual primary TSR sphere was dissociated and reseeded $(1000$ cells $/ 3.5 \mathrm{~cm}$ dish) again for secondary sphere formation. For reactivation of CD133 expression, cells were treated with $5 \mu \mathrm{M}$ 5-Aza-2-deoxycitidine (5-Aza-dC; Sigma, St. Louis, MO, USA) for the initial 48 hours, and then in combination with 500nM Trichostatine A (TSA; Sigma) for an additional 24 hours.

\section{Plasmids}

pCR3.1-Uni-CD133 expression plasmid was kindly provided by Dr. Denis Corbeil [29]. pGL3 enh-P1, P2, and P3 were previously established [24]. To generate pGL3enh-P4 and $\mathrm{P} 5$ reporter gene constructs, $\mathrm{P} 4$ and $\mathrm{P} 5$ regions of human CD133 gene were amplified by PCR using genomic DNA isolated from human normal peripheral blood monocytes. Oligonucleotide primers were designed on the basis of DNA sequences \{GenBank: AY438641 for P4 and GenBank: AY438640 for P5\}. The PCR products were gelpurified, cloned into pCR-Blunt II-TOPO vector (Invitrogen, Carlsbad, CA, USA) verifying sequences, and subcloned into the pGL3 enhancer luciferase reporter plasmid (pGL3enh) (Promega, Madison, WI, USA). The reporter plasmids driven by $\mathrm{P} 5$ or its deleted forms (pGL3enh-P5-1068, -768, -368, -98, -25) and mutant plasmids of P5 for ETS binding core sequence (GGAA) such as pGL3enh-P5-98mEBS\#1, pGL3enh-P5-98mEBS \#2, and pGL3enh-P5-98mEBS \#1\#2, were constructed by PCRbased methods. The cDNA encoding the dominant negative forms of Ets2 (corresponding to amino acid residues 332-469) and Elk1 (corresponding to amino acid residues 1-168), which lack the transcriptional activation domain, were amplified from human brain cDNA and inserted into XhoI and NotI sites of the pCXN2-Flag expression plasmid [30]. For retrovirus-mediated transfer of Ets 2 and CD133 genes into NHA/TS cells, the each cDNA amplified from human brain cDNA and pCR3.1-Uni-CD133 
vector was subcloned into $\mathrm{pCX} 4$ pur retroviral vector kindly provided by Dr. Tsuyoshi Akagi [31].

\section{RNA extraction and semiquantitative RT-PCR}

RNA was isolated with TRI Reagent (Sigma) according to the manufacturer's instructions. After oligo(dT)primed reverse transcription of $4 \mu \mathrm{g}$ of total RNA was conducted, the resulting single-stranded cDNA was amplified by PCR using KOD-Plus DNA polymerase (TOYOBO, Osaka, Japan). The specific primers are listed in Additional file 1, Figure S1.

\section{Immunoblotting}

Immunoblotting was performed as described previously [32]. Briefly, cells were lysed and protein concentration of lysates was determined by Protein Assay reagent (Bio-Rad, Richmond, CA, USA). Thirty $\mu \mathrm{g}$ of proteins were separated by SDS-PAGE and transferred to a polyvinylidene difluoride filter, which was subsequently incubated with Tris-HCl-based buffer ( $\mathrm{pH}$ 7.4) containing 5\% dried nonfat milk for 1 hour at room temperature (RT). Filters were probed with mouse monoclonal antibodies to CD133 (1: 200; Miltenyi Biotec, Auburn, CA, USA), Flag M2 (1: 1000; Sigma), and Actin (1: 2500; Chemicon, Temecula, CA, USA), or rabbit polyclonal antibodies to ERK1 (1: 200; Santa Cruz Biotechnology, Santa Cruz, CA, USA) and phospho-p44/p42 MAPK (1: 1000; Cell Signaling). Bound antibodies were detected with peroxidase-labeled goat antibody to mouse IgG or goat antibody to rabbit IgG and visualized by enhanced chemiluminescence reagents (Amersham Pharmacia Biotech, Freiburg, Germany).

\section{Luciferase reporter assay}

Dual-luciferase reporter assay was performed as described previously [33]. Briefly, cells plated on 24-well plates were transiently transfected with both of $C D 133$ promoter-firefly luciferase plasmids and internal control plasmid as pRL-TK (Promega) encoding Renilla luciferase for monitoring transfection efficiency. After 48 hours, luciferase activity was measured, and the ratio of firefly activity normalized with the Renilla activity was calculated for each transfection. In the experiments using Ets dominant negative constructs and U0126, single reporter assay system was conducted to exclude the possibility that pRL-TK control vector could be affected by the change of Ets expression, by normalizing firefly activity to protein concentration of cell lysate for each transfection or treatment.

\section{Electrophoretic mobility shift assay (EMSA)}

Nuclear extracts were prepared as described previously [33]. All synthetic oligonucleotides were annealed and end-labeled by T4 polynucleotide kinase (Promega) with $\left[\gamma-{ }^{32} \mathrm{P}\right]$ ATP (Amersham). The following 25 bp oligonucleotides (double strand DNA) were used for experiments: EBS1, 5'-ATCAGGCAGGAAGGGTAGAATGCTG-3' (position -62 to -38 of $\overline{C D 133} \mathrm{P} 5$ promoter); mEBS1, 5'ATCAGGCATTAAGGGTAGAATGCTG-3' (position -62 to -38 of $C D 133 \mathrm{P} 5$ promoter with mutated Ets site); EBS2, 5'-TGCTGGGACAGGAAGTAGCTTGGAG-3' (position -42 to -18 of CD133 P5 promoter); mEBS2, 5'TGCTGGGACATTAAGTAGCTTGGAG-3' (position -42 to -18 of $C D 133$ P5 promoter with mutated Ets site); Cons. EBS, 5'-GGGCTGCTTGAGGAAGTATAAGAAT3 ' (Ets responsive element of the human erbB2 promoter [34]); and -25/-1, 5'-GCTTGGAGGTGGGCCT TAGGCTGGT-3' (position -25 to - 10 of the CD133 P5 promoter without Ets site). Nuclear extracts containing $10 \mu \mathrm{g}$ of proteins were incubated for 20 minutes at RT with $\sim 100,000 \mathrm{cpm}$ of the labeled probe in a final volume of $20 \mu \mathrm{l}$ of $10 \mathrm{mM}$ Tris- $\mathrm{HCl}$ (pH 7.5) buffer containing $50 \mathrm{mM} \mathrm{NaCl}, 1 \mathrm{mM}$ dithiothreitol, $1 \mathrm{mM}$ EDTA, 5\% glycerol, and $1 \mu \mathrm{g}$ poly $(\mathrm{dI}-\mathrm{dC})$ poly $(\mathrm{dI}-\mathrm{dC})$. For competition experiments, 50 -fold molar excess of the cold oligonucleotide was added to the nuclear extracts 10 minutes prior to addition of the labeled probe. The reacted probes were subjected to electrophoresis $\left(250 \mathrm{~V}\right.$ for 90 minutes at $4^{\circ} \mathrm{C}$ ) on a non-denaturing, $5 \%$ polyacrylamide gel containing 1xTGE (25 mM Tris- $\mathrm{HCl}, 190 \mathrm{mM}$ glycine, 1 mM EGTA) buffer.

\section{Magnetic and fluorescence activated cell sorting}

For enrichment of CD133-expressing cells, Fuji cells were subjected to immunomagnetic separation using a magnetic activated cell sorting (MACS) CD133 Cell Isolation Kit (Miltenyi Biotec), according to the manufacturer's protocol. Briefly, dissociated cells incubated for 30 minutes at $37^{\circ} \mathrm{C}$ were labeled with $\mathrm{CD} 133 / 1$ Micro Beads. After washing, labeled cells were loaded onto a column installed in a magnetic field. Trapped cells were collected as CD133high fraction after the column was removed from the magnet. The collected cells were applied to a second column and the purification step was repeated. The flow-through of the MACS column is used as CD133low fraction. To check the expression of CD133, cells were stained with phycoerythrin (PE)-conjugated monoclonal antibodies for human CD133 (CD133/2-PE, Miltenyi Biotec) or isotype control antibody IgG2b-PE (Miltenyi Biotec) $\left(1: 10\right.$ diluted $4^{\circ} \mathrm{C}$ for 10 minutes in the dark). After washing, the labeled cells were analyzed by a BD FACS Aria flow cytometer (BD Biosciences, San Jose, CA, USA).

\section{Side population (SP) analysis}

To measure the proportion of SP cells, cells were stained with Hoechst 33342 dye (Molecular Probes, 
Eugene, OR, USA) as previously described [35]. Briefly, cells $\left(1 \times 10^{6}\right.$ cells $\left./ \mathrm{ml}\right)$ were resuspended in pre-warmed DMEM with $2 \%$ FBS. Hoechst 33342 was added at a final concentration of $5 \mu \mathrm{g} / \mathrm{ml}$ in the presence or absence of $50 \mu \mathrm{M}$ verapamil (Sigma) and the cells were incubated at $37^{\circ} \mathrm{C}$ for 90 minutes. After incubation, cells were washed and resuspended in cold DMEM with $2 \%$ FBS. Propidium iodide (Molecular Probes) at a final concentration of $1 \mu \mathrm{g} / \mathrm{ml}$ was added to discriminate dead cells. Analyses were performed on a BD FACS Aria SORP flow cytometer (BD Biosciences). The Hoechst dye was excited with the UV laser and its fluorescence was measured with a 405/20 nm band pass filter (Hoechst blue) and a $670 \mathrm{~nm}$ long pass filter (Hoechst red). Cells were pre-gated through FSC-W vs. FSC-H, and SSC-W vs. SSC-H dot plot to exclude doublet cells.

\section{Soft-agar colony formation assay}

Colony formation assay was performed as described previously [33]. Briefly, cells $\left(4 \times 10^{4}\right.$ cells per $6 \mathrm{~cm}$-dish $)$ were suspended in $0.36 \%$ noble agar, and plated on $0.6 \%$ bacto agar. Colonies were stained with dimethylthiazoldiphenyltetrazolium (MTT), and photographed by Fuji LAS-1000 imaging system. Colony numbers were calculated by using Multigauge Colony Count Software.

\section{In vivo tumor formation analysis}

Animal procedures were performed according to a protocol approved by the institutional Animal Care and Use Committee at Hokkaido University Graduate School of Medicine. $5 \times 10^{6}$ cells were mixed with matrigel (BD Biosciences) and subcutaneously injected into female nonobese diabetic/severe combined immunodeficiency (NOD/SCID) mice at 6-8 weeks of age. Tumor formation was assessed at 6 weeks after inoculation.

\section{Statistical analysis and computer analysis}

Comparison between experimental groups was made by Student's t-test. $\mathrm{p}<0.05$ was considered significant. The TFSEARCH program http://www.cbrc.jp/research/db/ TFSEARCHJ.html was used for analysis of possible binding sites of transcription factors.

\section{Results}

P5 exhibits the highest activity among the five putative promoters of $C D 133$ gene

To analyze the transcriptional machinery of $C D 133$ gene, we used a human colon carcinoma cell line Caco2 and a human synovial sarcoma cell line Fuji, because both cell lines express abundant CD133 transcripts and proteins, and also $\mathrm{CD} 133^{+}$Caco- 2 cells are reported to be able to generate tumors following transplantation in mice, whereas CD133- cells are not [36]. Our previous studies showed that Caco-2 expresses the transcripts containing all variants of exon 1 , and Fuji expresses only exons $1 \mathrm{~A}, 1 \mathrm{~B}, 1 \mathrm{C}$, and $1 \mathrm{E}$ (Figure 1D). Immunoblotting and RT-PCR analysis confirmed that the expression levels of CD133 mRNA and protein in Caco-2 cells are higher than those in Fuji cells (Figure 1A, Figure 1B). FACS analysis using anti-CD133 antibody revealed that both cell lines exhibit the cellular heterogeneity for CD133 expression (Figure 1C), as the CD133 positive fraction is $88.9 \%$ and $18.2 \%$ in Caco 2 and Fuji cells, respectively. Luciferase assay demonstrated a remarkable activation of P5 (pGL3enh-P5-1368) and a modest activation of P1 (pGL3enh-P1-1182), and no significant enhancement of P2 (pGL3enh-P2-253) and P3 (pGL3enh-P3-199) was detected in both cells (Figure 1E). A modest activation of P4 (pGL3enh-P4-1451) was observed only in Caco-2 cells, which probably contributes to the expression of exon 1D-containing transcripts.

\section{Ets binding motifs are required for CD133 P5 activity}

To determine the minimal region essential for P5 promoter activity, we generated a series of deletion mutants of P5 promoter (pGL3enh-P5-1068, -768, -368, -98, and $-25)$ and found that deletion to -98 holds a similar luciferase activity to the full-length promoter (pGL3enh-P5), but the further deletion to -25 leads to a significant reduction of activity (Figure $2 \mathrm{~A}$ ), suggesting that the region between -98 and -25 contains minimal elements required for CD133 transcription through P5 promoter.

The region between -98 to -25 contains two consensus binding motifs of Ets family proteins $(\mathrm{G} / \mathrm{C})(\mathrm{A} / \mathrm{C})$ GGAAG(G/T) (Additional file 1, Figure S2A) [37]. To determine whether these Ets motifs are necessary for P5 activity, we introduced a substitutional mutation altering two nucleotides of Ets core sequence GGAA to TTAA, into each or both of the Ets binding sites, designated as pGL3enh-P5-98mEBS\#1, \#2, and \#1\#2. Introduction of the mutation at EBS\#1 moderately decreased P5 promoter activity and the mutation at EBS\#2 remarkably decreased the activity (Figure 2B). These results indicated that the two Ets binding motifs are required for the P5 activity, and that in particular, mutation of EBS\#2 resulted in the greatest reduction of P5 activity.

\section{Specific binding of nuclear factors to an Ets motif \#2 in CD133 P5}

Next, to investigate the specific transcription factor which binds to EBS between -98 to -25 of P5, EMSA was performed using nuclear proteins extracted from Caco-2 and Fuji cells. A 25-bp double-stranded oligoDNA containing putative Ets binding sites was synthesized as probes or as unlabeled competitors (Additional file 1, Figure S2B). As shown in Figure 2C, an EBS2 probe, which was designed to span the $-42 /-18$ 

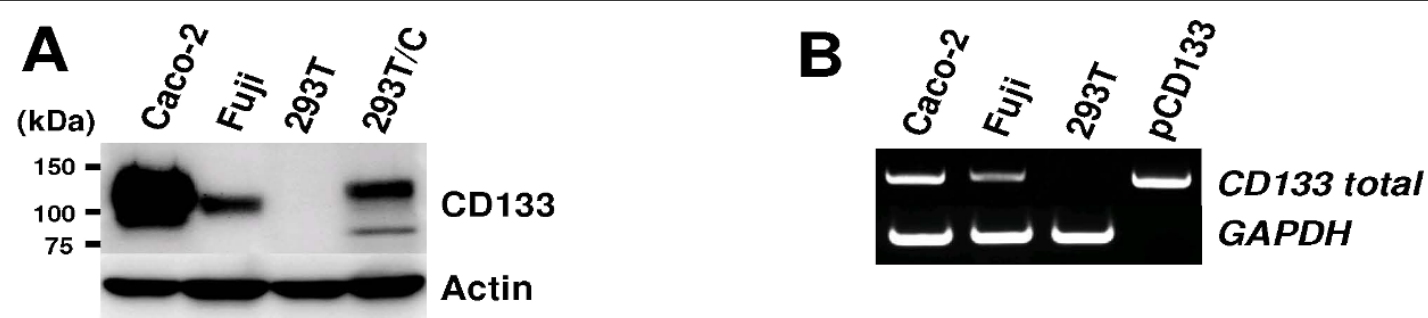

C Caco-2

\section{Fuji}

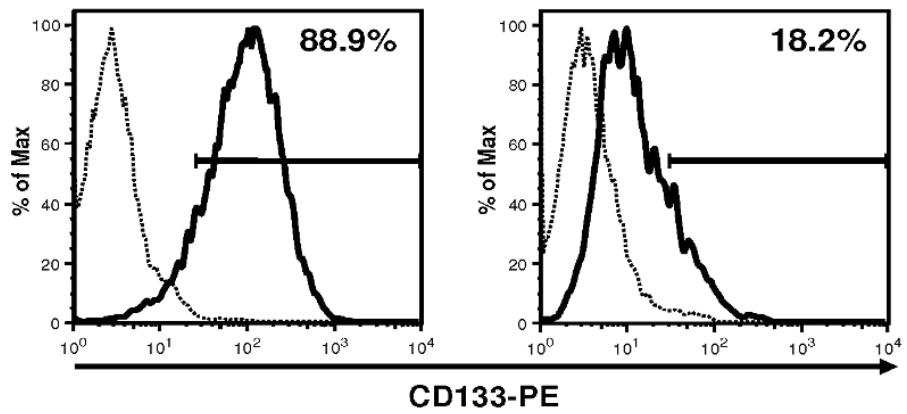

D

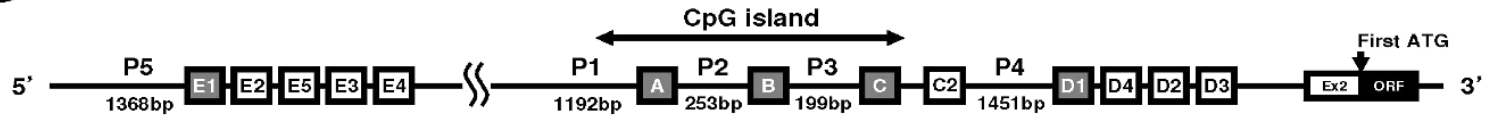

$\mathbf{E}$
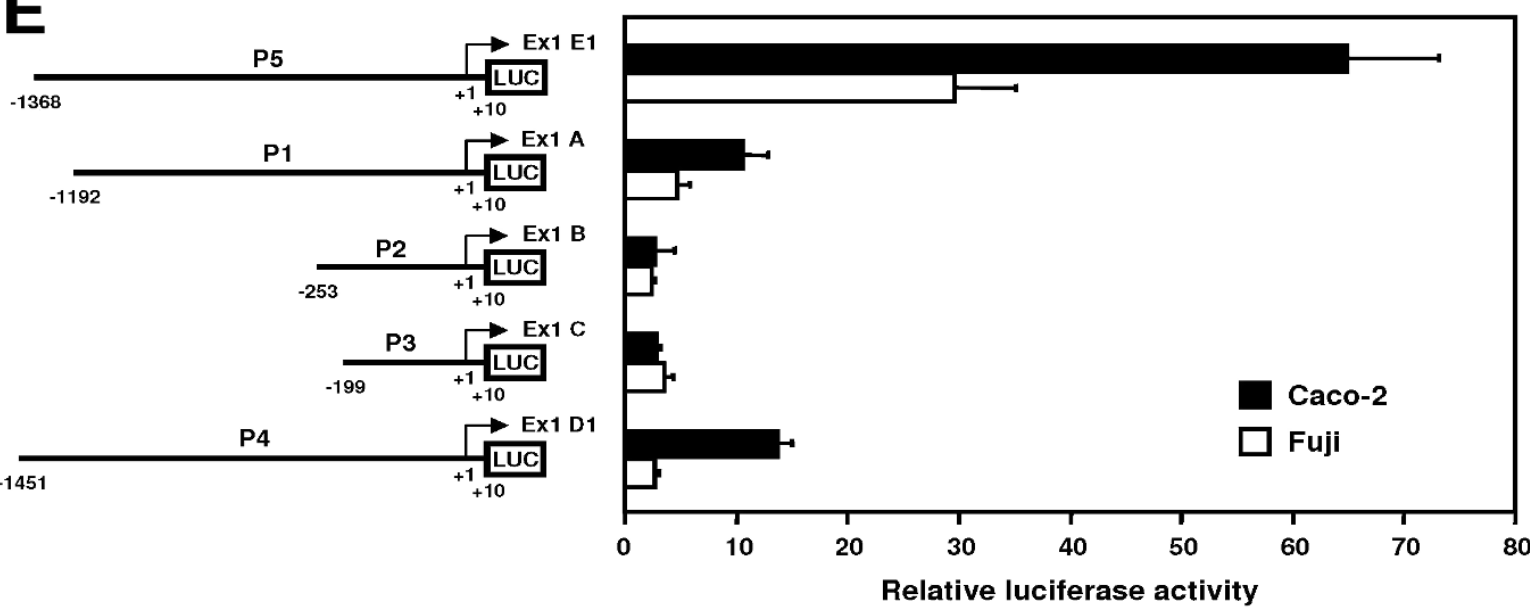

Figure 1 Expression and promoter activities of CD133 gene in human colon carcinoma Caco-2 and synovial sarcoma Fuji cell lines A, Immunoblot analysis of CD133 protein in Caco-2 and Fuji cell lines. Human kidney cell line 293T and 293T transfected with pCR3.1-Uni-CD133 (293T/C) was used as a negative and a positive control, respectively. Actin is an internal control. B, Semiquantitative RT-PCR analysis of CD133 mRNA in Caco-2 and Fuji cell lines. CDNA from 293T and 100 ng of pCR3.1-Uni-CD133 plasmid (pCD133) were used as a negative and a positive control, respectively. The number of PCR cycles was at 32 for CD133. GAPDH is an internal control. C, FACS analysis of Caco-2 and Fuji lines with CD133/2-PE antibody. Numbers indicate the percentage of CD133-positive cells in the total population. The bold line represents a staining with CD133-PE antibody, and the dotted line represents the isotype control antibody. D, Schematic representation of the position of five CD133 promoters (P1 to P5) and exon1s (A to E). Gray boxes represent five first exons starting from the transcriptional start positions. Exons 1C2, 1D4, and 1E5 were identified in our previous study [24]. E, Promoter activity of P1, P2, P3, P4, and P5 in Caco-2 and Fuji cell lines. Left panel, schematic representation of luciferase reporter plasmids containing five CD133 promoters. +1 indicates the transcription start position of each exon1s. Right panel, luciferase activities of Caco-2 and Fuji cells transfected with five indicated reporters. Data are means \pm s.d. of values from three independent experiments. 


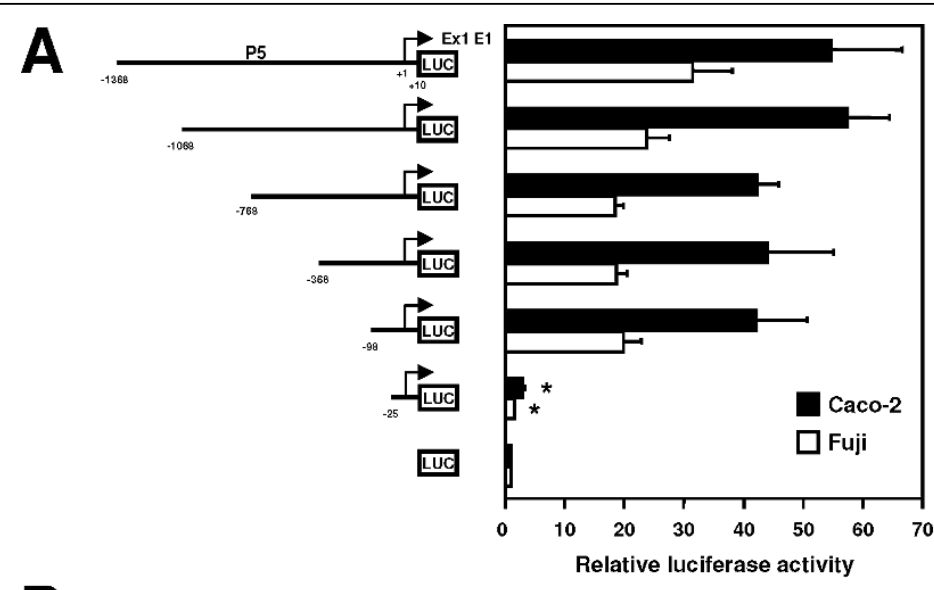

B

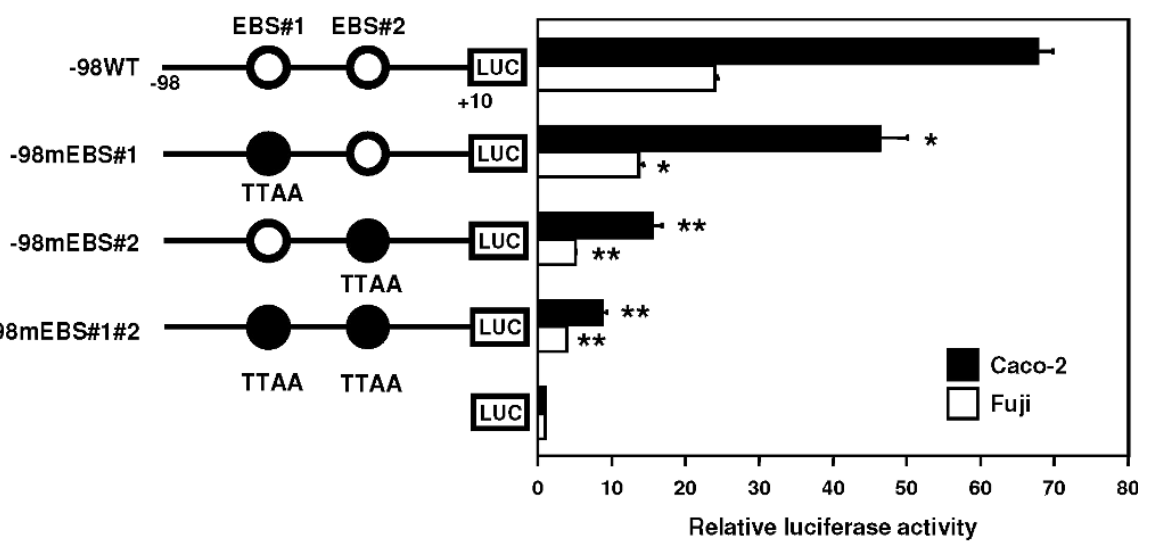

C

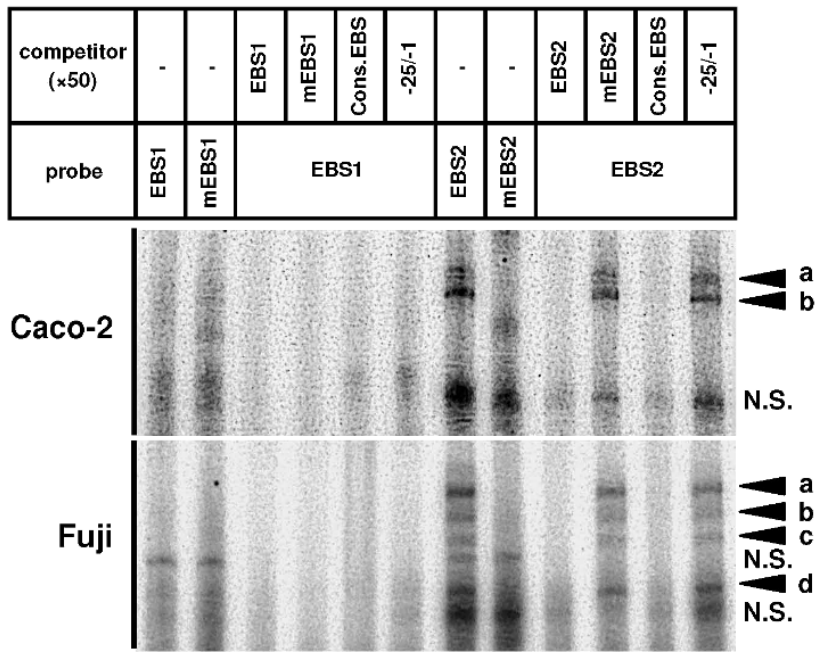

Figure 2 Identification of Ets binding motifs essential for CD133 P5 activity. A, Deletion analysis of the promoter activity of CD133 P5. Left panel, schematic representation of luciferase reporter constructs containing the deleted sequence of P5 region. +1 indicates the transcription start position of exon1E1. Right panel, luciferase activities of Caco-2 and Fuji cells transfected with a series of deletion mutants. Data are means \pm s.d. of values from three independent experiments. ${ }^{*} P<0.05$. B. Effects of mutation of Ets binding sites in the $-98 /-25$ region of the CD133 P5 on the transcriptional activity. Left panel, schematic representation of P5-98-based luciferase reporter constructs containing point mutation in two Ets binding sites (EBS\#1 and EBS\#2). Open circles represent wild-type sequence (GGAA) and closed circles represent substituted sequence (TTAA). Right panel, luciferase activities of Caco- 2 and Fuji cells transfected with the indicated mutant plasmids. ${ }^{*} P<0.05,{ }^{* *} P<0.01$. C, EMSA analysis of nuclear proteins binding to oligonucleotides containing the Ets binding site of the CD133 P5. The arrowheads a to $d$ indicate specific complexes of nuclear proteins with GGAA sequence in EBS\#2. N.S.: non-specific binding of proteins. 
region containing one proximal Ets motif (EBS\#2), showed two major shifted bands following incubation with the nuclear extract from Caco-2 (upper panel, bands a and b), but the EBS1 probe did not. In addition, these signals were eliminated by the use of mutant probes (mEBS2) and by competition using ETS consensus oligonucleotides (Cons. EBS) [34], as well as by 50fold molar excess amounts of cold wild-type EBS2 probe. -25/-1 oligonucleotides without Ets binding sequence were not able to affect them. These data indicate that the EBS\#2, and not EBS\#1, is critical for the complex formation on the CD133 P5 region. Interestingly, four complexes were obtained using the nuclear extracts from Fuji under the same conditions (lower panel, bands a-d), in which complexes a and b appeared to have similar mobility with those in Caco-2. These results demonstrated that both tumor cell lines express any factors that can bind to the EBS in CD133 P5 promoter, although there is a subtle difference in their preferred binding sequence.

\section{Dominant negative forms of Ets proteins interfere with CD133 P5 activity}

Ets family proteins share a conserved DNA-binding domain (ETS domain) that recognizes a GGAA sequence. To determine the implication of Ets factors to regulate $C D 133$ transcription, the expression levels of 21 human Ets genes were examined by semi-quantitative RT-PCR (Figure 3A and Additional file 1, Figure S3), in Caco-2 and Fuji which was separated by the expression
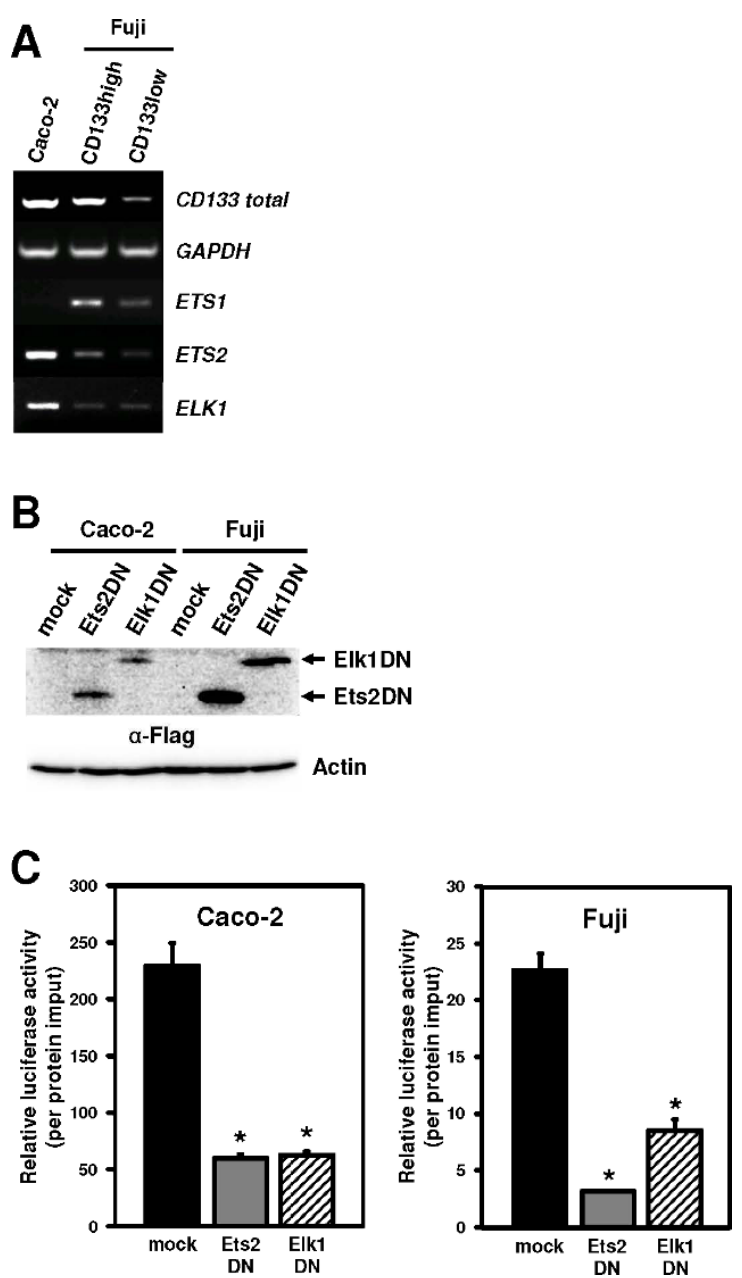

Figure 3 Dominant negative Ets proteins inhibit CD133 P5 activity. A, mRNA expression of ETS1, ETS2, and ELK1 genes in Caco-2 and Fuji cells. Expression pattern of 21 Ets family genes was analyzed by semi-quantitative RT-PCR analysis, in which Fuji cells with a high level of CD133 expression (CD133high) were enriched by MACS. The expression of the other genes except for ETS1, ETS2, and ELK1 are shown in Additional file 1, Figure S3. B, Transient overexpression of dominant negative Ets2 (Ets2DN) and Elk1 (Elk1DN) in Caco-2 and Fuji cell lines. Cells were transfected with pCXN2-Flag-Ets2DN and -Elk1DN lacking a transcription activation domain. The expression was evaluated by immunoblot analysis using anti-Flag antibody. C, Effects of dominant negative Ets2 and Elk1 on P5 promoter activity. P5 reporter plasmids were co-transfected with dominant negative ETS mutants. Data are means \pm s.d. of values from three independent experiments. ${ }^{*} P<0.01$ vs. mock-transfected cells. 
amount of CD133 by the MACS system. Ets members were found to be expressed in both tumor lines, but the expression of ETS1, ELK3, ER81, ERG, and FLI1 genes were not detected in Caco- 2 cells. Comparing the CD133high fraction with CD133low in Fuji cells, it was revealed that ETS1, ETS2, ELF2, ESE1, ELF4, ERG, FLI1, and $F E V$ genes were highly expressed in the CD133expressing population.

To test whether Ets proteins could specifically mediate P5 transcription, we used a transient transfection approach, employing dominant-negative Ets2 (Ets2DN) and Elk1 (Elk1DN) lacking a transactivation domain. Expression of Ets2DN and Elk1DN resulted in significant inhibition of P5 activity in both cell lines (Figure $3 B$, Figure 3C). Since the use of dominant negative Ets constructs can broadly interfere with the function of multiple Ets factors [38], studies utilizing dominant negative forms of Ets cannot identify which members of the Ets family are actually important. Therefore, these results indicate that any Ets factors with ETS domain are required for P5 activity. In addition, the partial decrease of P5 activity by EtsDN constructs might reflect the presence of any redundant factors to achieve P5 transcription.

\section{MEK/ERK pathway is necessary for CD133 transcription}

As several Ets factors, including Ets 2 and Elk1, have been shown to be activated through phosphorylation by ERK1/2 (also known as p44/42 MAPK), we examined the contribution of the ERK pathway to CD133 gene expression. ERK1/2 were constitutively activated without the external stimuli in both tumor cell lines, and this phosphorylation of ERK1/2 was diminished by the treatment of U0126 (Figure 4A), a potent and specific inhibitor of MEK1/2, which binds to MEK1 and MEK2 regardless of its activation state to inhibit ERK1/2 phosphorylation noncompetitively. Furthermore, to investigate the involvement of MEK/ERK signaling in P5 activity, reporter analysis was performed in the presence or absence of U0126. Treatment of Fuji cells with U0126 led to the marked inhibition of P5 activity (Figure 4B). No cell toxicity was observed concerning morphology and growth of both cell lines under the conditions of this experiment (data not shown). Consistently, U0126 also markedly decreased the expression of CD133 protein in Fuji cells (Figure 4C), indicating that the MEK/ERK signaling is implicated in P5-mediated CD133 expression. In contrast, the same concentration of U0126 could not affect P5 activity and expression of CD133 in Caco-2 cells, suggesting that another pathway could regulate Ets-mediated P5 transcription in Caco-2 cells. However, it remains possible that the ERK pathway might simultaneously regulate other promoters (P1 to P4). In fact, ERK inhibition decreased the expression of exon 1B- and 1D- and 1E-containing CD133 mRNA, but increase exon $1 \mathrm{C}$-containing one (Additional file 1 , Figure S4). These data indicate cell type-specific regulation of CD133 gene expression by the ERK pathway.

\section{Inhibition of MEK/ERK pathway abolishes side population in Caco-2 cells}

To assure the relevance of the ERK pathway to stem-like characteristics, the effect of U0126 on the amount of SP was assessed by flow cytometric analysis. The SP fraction in tumor cells has been known to define the population containing stem-like cells, which highly express ATP-binding cassette (ABC) transporters to efflux both Hoechst dye and chemotherapeutic agents, and to have a high capacity to form tumor xenografts in mice [39]. In our experiments, the side population represented approximately $2 \%$ in the Caco- 2 cell line (Figure $4 \mathrm{D}$, Figure 4E). Treatment with verapamil, an inhibitor of the $\mathrm{ABC}$ transporters, completely ablated this population. In contrast, no distinct SP was visible in the Fuji cell line (data not shown). Treatment of Caco-2 with U0126 dramatically reduced the SP frequency to $0.15 \%$ (Figure 4D, Figure 4E). This result emphasized our conclusion that ERK is a key molecule in the signal transduction to maintain stem-like features in tumor cells.

\section{Ets2 increases CD133 mRNA levels in human astrocytes,} but cannot confer tumorigenicity

To examine whether Ets factor could increase CD133 expression and confer tumorigenicity in normal cells, we established the immortalized human astrocytes overexpressing Ets2 (NHA/TSE2). The increase of CD133 mRNA expression was detected in NHA/TSE2 comparing to NHA/TS cells and its effect was strongly enhanced by the treatment with demethylating agent 5Aza-dC and histone deacetyltransferase inhibitor TSA (Figure 5A). 5Aza-dC/TSA treatment has been shown to open the chromosomal region to increase accessibility for transcription factor complexes to assemble at the promoter and drive gene transcription. However, the elevated protein level of CD133 could not be detected by FACS analysis (Additional file 1, Figure S5). Instead, approximately $0.04 \%$ of side population diminished by verapamil was observed in the NHA/TSE2 cells, whereas substantial SP was not visible in NHA/TS cells (Additional file 1, Figure S6). To assess the potential of Ets2 on tumorigenicity, NHA/TSE2 cells were subcutaneously implanted into NOD/SCID mice. All positive control mice implanted with $5 \times 10^{6} \mathrm{NHA} / \mathrm{TSR}$ cells, which is a transformed astrocytes [27], developed tumors at 4-6 weeks with $100 \%$ incidence (4/4), whereas any of the mice injected with NHA/TS or NHA/TSE2 cells could not grew as tumors at least by 6 weeks $(0 / 4)$ (Figure $5 \mathrm{~B}$ ). These data indicate that Ets 2 is not 


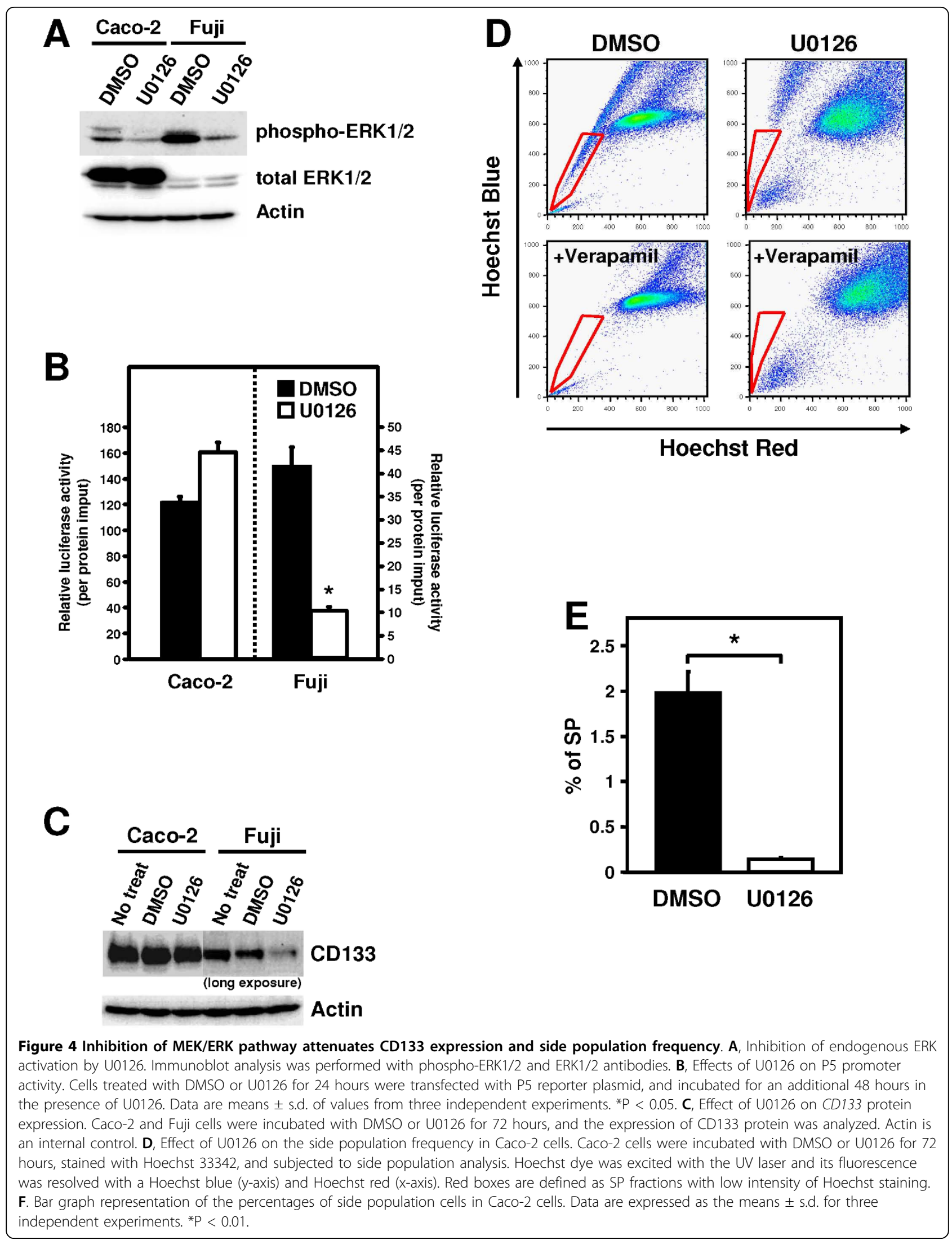




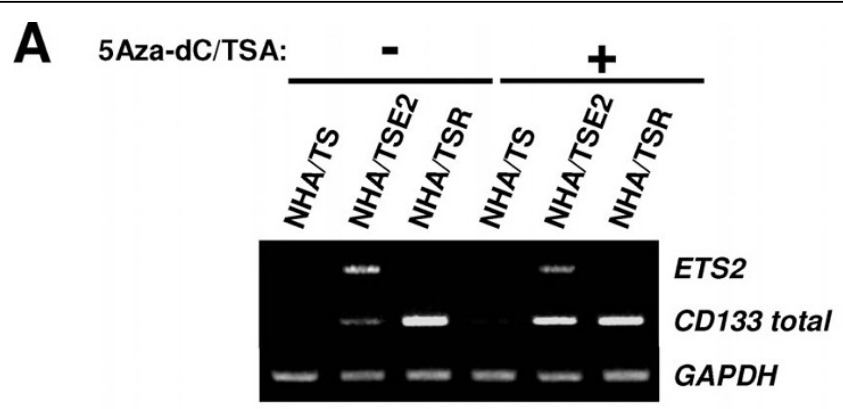

B

\begin{tabular}{cc}
\hline Cell lines & $\begin{array}{c}\text { Tumor development } \\
\text { in NOD/SCID mice }\end{array}$ \\
\hline NHA/TS & $0 / 4$ \\
NHA/TSE2 & $0 / 4$ \\
NHA/TSR & $4 / 4$ \\
NHA/TSC & $0 / 4$ \\
\hline
\end{tabular}

C

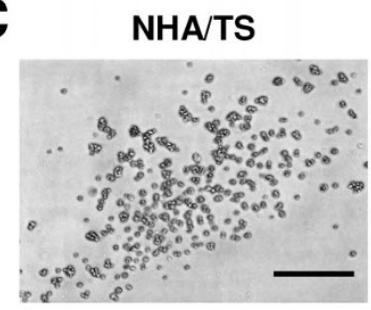

D

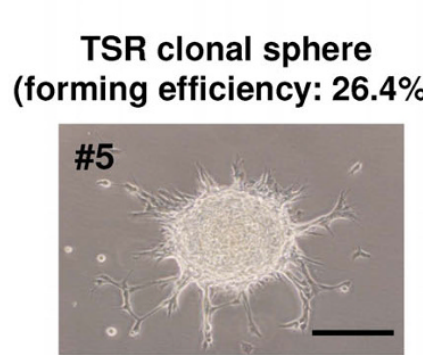

NHA/TSR

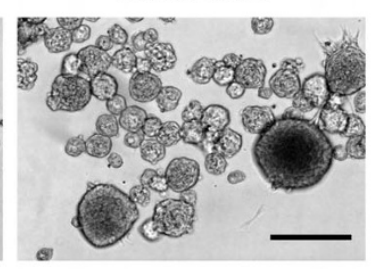

E
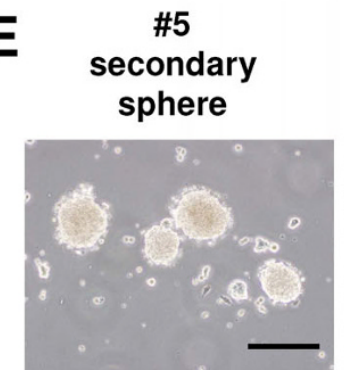

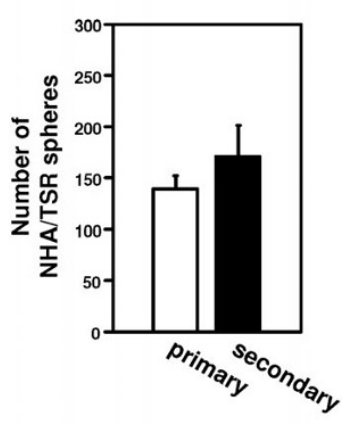

\#5

$10 \%$ FBS differentiation

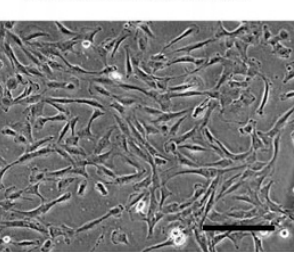

Figure 5 Ras-transformed astrocytes have an ability to form neurosphere-like colonies with the increased expression of CD133 mRNA. A, Expression of CD133 mRNA in NHA/TSE2 and NHA/TSR cells. The expression levels of CD133 mRNA were examined by semi-quantitative RTPCR analysis. The number of PCR cycle was 32 for CD133. GAPDH is an internal control. 5Aza-dC; 5-Aza-2-deoxycitidine. TSA; Trichostatine A. B, In vivo tumor formation analysis. $5 \times 10^{6}$ of each cells were subcutaneously injected into NOD/SCID mice. Tumor formation was evaluated after 6 weeks of inoculation. The number of mice developing tumors/numbers of mice injected is shown. C, Representative images of NHA/TS and NHA/TSR cells cultured in neural stem cell medium. Bar graph shows mean \pm s.d. of the absolute number of primary and secondary TSR spheres, which was measured from three independent experiments. Cell clusters $\geq 50 \mu \mathrm{m}$ in diameter were counted as spheres. Secondary sphere assay was also performed at the same condition. Scale bar $=200 \mu \mathrm{m}$. D, Representative images of a sphere derived from single NHA/TSR cell. FACSpurified single NHA/TSR cell was cultured in NSC medium in a 48-well plate for 2 weeks. E, Individual TSR-derived clonal sphere was dissociated and reseeded in NSC medium (left) and in 10\%FBS-DMEM (right) to confirm the secondary sphere formation activity and differentiation potential, respectively. Scale bar $=200 \mu \mathrm{m}$. 
sufficient to fully transform normal human astrocytes, and thus the acquisition of tumor stem-like characters may be accomplished by synergistic actions of multiple factors.

\section{Human astrocytes transformed by oncogenic Ras can form neurosphere-like colonies with the increased expression of CD133 mRNA}

NHA/TSR cells form malignant tumors with features of human anaplastic astrocytoma, the WHO classification Grade III in mice [27] and malignant astrocytoma has been well-known to display a stem cell signature [2]. To confirm whether Ras-mediated transformation in human astrocytes could confer stem-like features in parallel with the acquisition of tumorigenicity, we examined the expression level of CD133 and the activity of neurosphere formation in NHA/TSR cells. In the absence of 5Aza-dC/TSA, the more substantial level of CD133 mRNA was detected in NHA/TSR cells comparing to NHA/TSE2 cells (Figure 5A), suggesting that Ras might play an additional role to modulate chromatin structure of CD133 promoter region. Actually, CD133 expression is regulated by promoter DNA methylation [24]. However, the protein level of CD133 could not be increased (Additional file 1, Figures S5 and S7), suggesting that Ras activation is also not sufficient to completely restore CD133 expression in human astrocytes. The generation of neurospheres is considered as an important symbol of in vitro neural stem cell culture, as well as an exhibition of self-renewal capacity [40]. After culturing in NSC medium containing bFGF and EGF for 2 weeks, NHA/TSR cells generated significantly greater neurosphere-like colonies (diameter is $\geq 50 \mu \mathrm{m}$ ) than NHA/ TS cells, and this capacity was maintained to generate secondary neurospheres (Figure $5 \mathrm{C}$ ). To except the possibility of cellular aggregates, single NHA/TSR cell was also sorted using flow cytometry and deposited into 48well plates containing NSC medium. NHA/TSR had a forming efficiency of $12.7 \pm 1.5$ (26.4\%) single spheres per 48-well plate, as opposed to zero for NHA/TS (Figure 5D). A single sphere could also maintain the capacity to form secondary spheres, as well as differentiate into adherent cells morphologically identical to original NHA/TSR cells in 10\% FBS-containing medium (Figure $5 \mathrm{E}$ ), indicating that constitutive activation of the Ras pathway can trigger the development of stem-like population with self-renewing ability to retain stemness, and possibly that human astrocytes could dedifferentiate to premature state following to the Ras-mediated transformation and/or its sequential combination with immortalization. Side population size was not increased in NHA/TSR cells (Additional file 1, Figure S6). These results indicate that the expression of CD133 protein and appearance of side population are not necessarily required for other tumor stem-like behaviors, at least for the capacity to form neurospheres in vitro and tumors in vivo. Finally, NHA/TS cells retrovirally overexpressed CD133 gene (NHA/TSC) could form a larger number of colonies comparing to NHA/TS cells in softagar colony formation assay (Additional file 1, Figure S7). However, their number and size are much less than those of NHA/TSR even after they were cultured for 3 weeks. In addition, mice subcutaneously implanted with $5 \times 10^{6} \mathrm{NHA} / \mathrm{TSC}$ cells could not develop any tumors at least by 6 weeks (Figure 5B), supporting the view that CD133 is just a concomitant marker for tumorigenic process.

\section{Discussion}

Traditionally, therapeutic procedures for human cancer have been performed based on the implicit understanding that the tumor population is homogeneous. However, emerging evidence has suggested that tumors are hierarchically organized and the capacity of tumor propagation depends mainly on a sub-population of stemlike cells. The discovery of stem-like cells in solid tumors convincingly accounts for chemoresistance, and recurrence arose in a number of human cancers. Many studies have been carried out using stem-like population enriched by a stem cell marker CD133, and these have demonstrated an increased resistance of $\mathrm{CD}_{133^{+}}$stemlike tumor cells to treatment with chemotherapeutic agents compared with CD133 tumor progenies. In addition, the side population has been also used as one of the methods to enrich the stem-like tumor cells, as well as normal stem cells, and is defined by Hoechst dye exclusion property. Although it remains to be clarified whether the expression of CD133 and transporter molecules directly contribute to tumor progression, the regulatory mechanism of stem-related gene expression could help our understanding of tumor stemness and should be investigated further to improve the development of eradicative therapies against human malignancies.

Previously, we and other investigators reported that the expression levels of CD133 mRNA are positively correlated with tumor stage and the poor prognosis of patients [24,41-47]. However, it is still controversial whether CD133 is just a concomitant marker for tumorigenic process or whether it directly leads to tumorigenesis. To examine the role of CD133 expression in normal cells, we established NHA/TSC cells and found that overexpression of CD133 is not sufficient to induce tumorigenic transformation in vivo (Figure 5B and Additional file 1, Figure S7). Interestingly, a recent study using genetically engineered mice suggested that CD133 is just a concomitant marker of stem-like cells. Tumors had developed throughout the entire intestine when Wnt signaling was selectively activated in $\mathrm{CD} 133^{+}$ 
or $\mathrm{Lgr}^{+}$adult small intestinal stem cells [21,48]. In contrast, carcinomas with lower malignancy were found in less than one in five mice when the same system was targeted to non-stem cells [48]. Therefore, it is conceivable that malignant expansion of tumors depends on the latent potential of adult stem cells to proliferate or differentiate, and thus the increase of CD133 mRNA in a higher stage of tumors might be a result of unregulated expansion of $\mathrm{CD} 133^{+}$stem-like cells. Considering that NHA/TSR cells possess the high activity to form neurospheres and tumors in mice without entire expression of CD133 protein (Figure 5), these data would support the view that CD133 is just a marker of stem-like cells.

The expression mechanisms of $C D 133$ gene have not been examined so far, despite its expression being recognized as an important stem-related biomarker for a number of different cell lineages, probably because CD133-expressing cells are a very rare sub-population for transcriptional analysis. In addition, we observed some culture effects, in that serial passages of primary glioblastoma culture easily diminished CD133 expression (data not shown). The two tumor cell lines used in this study stably preserve a high proportion of CD133 ${ }^{+}$-proliferating cells, and they could be useful tools to further investigate the expression machinery for CD133.

In Figure 1D, we have shown that P5 promoter exhibits the highest activity among the five alternative promoters, but it should be noted that P5 does not necessarily predominate the CD133 expression. First, the stability and translational efficiency of CD133 mRNA might be varied by 5 '-UTR sequences containing exon1s $(1 \mathrm{~A}, 1 \mathrm{~B}, 1 \mathrm{C}, 1 \mathrm{D}$, or $1 \mathrm{E})$. Indeed, the modulation of 5'-UTR involves in the regulated expression of some proteins regulating growth and differentiation of normal stem cells and plays a role in the progression of specific types of cancers, such as leukemia and prostate cancer [49]. Therefore, the role of each exon1 on CD133 expression needs to be determined. Experiments should be limited to the use of the whole locus including all of exon1s for reporter assay.

Second, epigenetic modifications such as DNA methylation and histone modification have been reported to play important roles in the regulation of various genes [50]. However, it is questionable that the physiological status of chromatin complexes is accurately reconstituted in the transient reporter assay system. Indeed, we reported that the expression levels of CD133 mRNA were dramatically restored by the treatment of glioma cell lines with the demethylating agent 5-azacytidine and/or histone deacetylase inhibitor valproic acid [24]. Therefore, it might be possible that epigenetic modification is the final determinant of CD133 gene expression and stem-like features. Further studies are needed to address the molecular mechanisms to epigenetically maintain the active state of $C D 133$ gene, containing demethylases of DNAs and/or acethyltransferases of histones.

The Ras/ERK pathway plays a crucial role in transducing signals from various external stimuli to control cell adhesion, proliferation, migration, and survival. It is well-known to be deregulated in some types of human tumors [51]; Ras mutations are found in $45 \%$ of colon carcinomas and $90 \%$ of pancreatic cancers; Raf mutations are found in two-thirds of melanomas, where TSLCs have been enriched by sorting for CD133 protein expression. The Ras pathway was also reported to be involved in stem cell regulation. Undifferentiated human embryonic stem cells (hESCs) require a growth factor FGF, which transmits signals mainly by the Ras/ERK pathway [52]. Indeed, ERK is active in undifferentiated hESCs and inhibition of the ERK pathway with U0126 caused extensive cell death and differentiation [53].

It is noteworthy that myeloproliferative disorders could be initiated by K-Ras(G12D) in a highly restricted population enriched for hematopoietic stem cells (HSCs) [54]. The expression of activated M-Ras in HSCs initiated leukemogenic transformation [55]. In addition, sophisticated mouse tumor models triggered by oncogenic Ras have demonstrated the contribution of the Ras/ERK pathway to the acquisition of cancer stem cell properties, in primary human mammary epithelial cells (HMECs) [56]. H-RasV12 also causes the p53knockout mouse-derived astrocytes to be transformed into brain tumor stem-like cells, in which MEK/ERK pathway is responsible for neurosphere formation [57]. Interestingly, let-7 microRNA, known to downregulate Ras, reduces proliferation, sphere formation, and the proportion of undifferentiated cells in vitro and tumor formation and metastasis in vivo [58]. These reports support that the Ras/ERK pathway plays a central role to acquire and maintain tumor stem-like properties.

Furthermore, we have shown that ERK inhibition diminishes the frequency of the side population, but we could not reveal the detailed mechanisms. RT-PCR analysis revealed that the expression of $\mathrm{ABCC} 1 \mathrm{mRNA}$ was decreased by U0126 treatment, while that of ABCG2 mRNA was increased in Caco-2 cells (data not shown). Although it has not been elucidated which transporters have a dominant role for SP phenotype in Caco-2 cells, the ERK pathway might regulate multiple events at the upstream of the SP phenotype, including gene transcription and protein stabilization. Actually, it has been reported that inhibition of the Ras/ERK pathway also promotes $\mathrm{ABCB} 1$ protein degradation to diminish the cellular multidrug resistance in the human colorectal cancer cell lines [59]. SP cells are also known to reproduce NSP cells [35]. Therefore, U0126 might affect the 
division patterns of SP cells via the decrease of selfrenewal and/or the increase of differentiation. In the future, we will clarify these points, and should examine whether the therapeutic approaches to Ras/ERK inhibition could be effective for eradication of stem-like cells in tumor mass.

In this study, we found that the Ras/ERK pathway is implicated in at least one of the stem-like characteristics in all of the examined tumor cell lines: SP size in Caco2, CD133 expression in Fuji, and sphere and tumor forming activity in NHA/TSR cells. These finding suggest that Ras/ERK could be a common upstream pathway to govern the entirety of downstream characteristics. However, the contribution of Ras/ERK was varied in a cell type-specific manner; Ras/ERK does not contribute to $\mathrm{CD} 133$ protein expression in Caco-2 and NHA/TSR, and SP appearance in Fuji and NHS/ TSR cells. Crosstalk between ERK and other pathway specific to an individual type of tumors may result in the diversity of stem-like hallmarks.

\section{Conclusions}

This study has characterized the critical cis-acting element in CD133 promoter P5 and identified one potential pathway required for $C D 133$ gene regulation, side population maintenance, and spheres forming activity in stem cell culture. As CD133 expression is now recognized as one of the most important biomarkers for the enrichment of stem-like tumor cells, the Ets motifs and Ras/ERK pathway we identified in this study could lead to a more comprehensive understanding of the molecular basis of tumor stemness. Further characterization of the five $C D 133$ promoters, including protein-protein interactions and epigenetic regulations, must allow us to identify bona fide targets that define tumor stemness, and facilitate the development of TSLC-targeted therapies to eradicate human malignancies.

Additional file 1: Additional Figures. Figures S1-7 as referred to in the
main text.
Click here for file
[http://www.biomedcentral.com/content/supplementary/1476-4598-9-39-
S1.pdf]

\section{Acknowledgements}

We thank Dr. D. Corbeil for pCR3.1-Uni-CD133 vector, Dr. T. Akagi for pCX4pur vector, and Dr. M. Miyake for Caco-2 cell line. We are also grateful to M. Tanino, I. Nobuhisa, T. Kagawa, and other members of our laboratory for discussion. This work was supported by Grants-in-Aid for Scientific Research from the Ministry of Education, Culture, Sports, Science and Technology (MEXT) of Japan to KT, HN, TT, and ST, and also by a grant from the Global COE Program "Cell Fate Regulation Research and Education Unit" to KT and TT. Kouichi Tabu is a Research Fellow of the Japan Society for the Promotion of Science.

\section{Author details}

${ }^{1}$ Laboratory of Cancer Research, Department of Pathology, Hokkaido University Graduate School of Medicine, Kita-15, Nishi-7, Kita-ku, Sapporo, Japan. 'Department of Stem Cell Regulation, Medical Research Institute, Tokyo Medical and Dental University, 1-5-45 Yushima, Bunkyo-ku, Tokyo, Japan. ${ }^{3} \mathrm{Global}$ COE Program "Cell Fate Regulation Research and Education Unit", Kumamoto University, 2-2-1 Honjo, Kumamoto, Japan. ${ }^{4}$ Division of Cell Fate Modulation, Institute of Molecular Embryology and Genetics, Kumamoto University, 2-2-1 Honjo, Kumamoto, Japan. ${ }^{5}$ Research Group for Human Cell Transformation, KAN Research Institute Inc., Kobe MI R\&D Center, 6-7-3 Minatojima-Minamimachi, Chuo-ku, Kobe, Japan. ${ }^{6}$ Department of Translational Pathology, Hokkaido University Graduate School of Medicine, Kita-15, Nishi-7, Kita-ku, Sapporo, Japan.

\section{Authors' contributions}

$\mathrm{KT}$ designed the research, performed most of the experiments and data analyses, and drafted the manuscript. TK carried out MACS to separate CD133high and low Fuji cells and helped animal experiments. KS helped soft agar assay with human astrocytes and the editing of manuscript. LW helped cell cultures and plasmids extractions and performed animal experiments. NB helped ChIP assay. HN, $\mathrm{T}$, and ST contributed to the design of the entire study and the editing of the manuscript. All the authors have read the manuscript and agreed with its content.

\section{Competing interests}

The authors declare that they have no competing interests.

Received: 1 July 2009

Accepted: 19 February 2010 Published: 19 February 2010

\section{References}

1. Visvader JE, Lindeman GJ: Cancer stem cells in solid tumours: accumulating evidence and unresolved questions. Nat Rev Cancer 2008, 8:755-768.

2. Singh SK, Hawkins C, Clarke ID, Squire JA, Bayani J, Hide T, Henkelman RM, Cusimano MD, Dirks PB: Identification of human brain tumour initiating cells. Nature 2004, 432:396-401.

3. Collins AT, Berry PA, Hyde C, Stower MJ, Maitland NJ: Prospective identification of tumorigenic prostate cancer stem cells. Cancer Res 2005, 65:10946-10951.

4. Olempska M, Eisenach PA, Ammerpohl O, Ungefroren $H$, Fandrich $F$, Kalthoff H: Detection of tumor stem cell markers in pancreatic carcinoma cell lines. Hepatobiliary Pancreat Dis Int 2007, 6:92-97.

5. Yin S, Li J, Hu C, Chen X, Yao M, Yan M, Jiang G, Ge C, Xie H, Wan D, et al: CD133 positive hepatocellular carcinoma cells possess high capacity for tumorigenicity. Int J Cancer 2007, 120:1444-1450.

6. Ricci-Vitiani L, Lombardi DG, Pilozzi E, Biffoni M, Todaro M, Peschle C, De Maria R: Identification and expansion of human colon-cancer-initiating cells. Nature 2007, 445:111-115.

7. O'Brien CA, Pollett A, Gallinger S, Dick JE: A human colon cancer cell capable of initiating tumour growth in immunodeficient mice. Nature 2007, 445:106-110.

8. Monzani E, Facchetti F, Galmozzi E, Corsini E, Benetti A, Cavazzin C, Gritti A, Piccinini A, Porro D, Santinami M, et al: Melanoma contains CD133 and ABCG2 positive cells with enhanced tumourigenic potential. Eur J Cancer 2007, 43:935-946.

9. Jordan CT, Guzman ML, Noble M: Cancer stem cells. N Engl J Med 2006, 355:1253-1261

10. Dean M, Fojo T, Bates S: Tumour stem cells and drug resistance. Nat Rev Cancer 2005, 5:275-284.

11. Bao S, Wu Q, McLendon RE, Hao Y, Shi Q, Hjelmeland AB, Dewhirst MW, Bigner DD, Rich JN: Glioma stem cells promote radioresistance by preferential activation of the DNA damage response. Nature 2006, 444:756-760.

12. Diehn M, Clarke MF: Cancer stem cells and radiotherapy: new insights into tumor radioresistance. J Natl Cancer Inst 2006, 98:1755-1757.

13. Miraglia S, Godfrey W, Yin AH, Atkins K, Warnke R, Holden JT, Bray RA, Waller EK, Buck DW: A novel five-transmembrane hematopoietic stem cell antigen: isolation, characterization, and molecular cloning. Blood 1997, 90:5013-5021. 
14. Uchida N, Buck DW, He D, Reitsma MJ, Masek M, Phan TV, Tsukamoto AS, Gage FH, Weissman IL: Direct isolation of human central nervous system stem cells. Proc Natl Acad Sci USA 2000, 97:14720-14725.

15. Lee A, Kessler JD, Read TA, Kaiser C, Corbeil D, Huttner WB, Johnson JE, Wechsler-Reya RJ: Isolation of neural stem cells from the postnatal cerebellum. Nat Neurosci 2005, 8:723-729.

16. Sagrinati C, Netti GS, Mazzinghi B, Lazzeri E, Liotta F, Frosali F, Ronconi E, Meini C, Gacci M, Squecco R, et al: Isolation and characterization of multipotent progenitor cells from the Bowman's capsule of adult human kidneys. J Am Soc Nephrol 2006, 17:2443-2456.

17. Richardson GD, Robson CN, Lang SH, Neal DE, Maitland NJ, Collins AT: CD133, a novel marker for human prostatic epithelial stem cells. J Cell Sci 2004, 117:3539-3545.

18. Kordes C, Sawitza I, Muller-Marbach A, Ale-Agha N, Keitel V, KlonowskiStumpe H, Haussinger D: CD133+ hepatic stellate cells are progenitor cells. Biochem Biophys Res Commun 2007, 352:410-417.

19. Oshima Y, Suzuki A, Kawashimo K, Ishikawa M, Ohkohchi N, Taniguchi H: Isolation of mouse pancreatic ductal progenitor cells expressing CD133 and c-Met by flow cytometric cell sorting. Gastroenterology 2007, 132:720-732.

20. Ito $Y$, Hamazaki TS, Ohnuma K, Tamaki K, Asashima M, Okochi H: Isolation of murine hair-inducing cells using the cell surface marker prominin-1/ CD133. J Invest Dermatol 2007, 127:1052-1060.

21. Zhu L, Gibson P, Currle DS, Tong Y, Richardson RJ, Bayazitov IT, Poppleton H, Zakharenko S, Ellison DW, Gilbertson RJ: Prominin 1 marks intestinal stem cells that are susceptible to neoplastic transformation. Nature 2009, 457:603-607.

22. Zacchigna S, Oh H, Wilsch-Brauninger M, Missol-Kolka E, Jaszai J, Jansen S, Tanimoto N, Tonagel F, Seeliger M, Huttner WB, et al: Loss of the cholesterol-binding protein prominin-1/CD133 causes disk dysmorphogenesis and photoreceptor degeneration. J Neurosci 2009, 29:2297-2308

23. Shmelkov SV, Jun L, St Clair R, McGarrigle D, Derderian CA, Usenko JK, Costa C, Zhang F, Guo X, Rafii S: Alternative promoters regulate transcription of the gene that encodes stem cell surface protein AC133. Blood 2004, 103:2055-2061.

24. Tabu K, Sasai K, Kimura T, Wang L, Aoyanagi E, Kohsaka S, Tanino M, Nishihara H, Tanaka S: Promoter hypomethylation regulates CD133 expression in human gliomas. Cell Res 2008, 18:1037-1046.

25. Sementchenko VI, Watson DK: Ets target genes: past, present and future. Oncogene 2000, 19:6533-6548.

26. Seth $A$, Watson DK: ETS transcription factors and their emerging roles in human cancer. Eur J Cancer 2005, 41:2462-2478.

27. Sasai K, Akagi T, Aoyanagi E, Tabu K, Kaneko S, Tanaka S: O6methylguanine-DNA methyltransferase is downregulated in transformed astrocyte cells: implications for anti-glioma therapies. Mol Cancer 2007, 6:36.

28. Lee J, Kotliarova S, Kotliarov Y, Li A, Su Q, Donin NM, Pastorino S, Purow BW, Christopher N, Zhang W, et al: Tumor stem cells derived from glioblastomas cultured in bFGF and EGF more closely mirror the phenotype and genotype of primary tumors than do serum-cultured cell lines. Cancer Cell 2006, 9:391-403.

29. Corbeil D, Roper K, Hellwig A, Tavian M, Miraglia S, Watt SM, Simmons PJ, Peault B, Buck DW, Huttner WB: The human AC133 hematopoietic stem cell antigen is also expressed in epithelial cells and targeted to plasma membrane protrusions. J Biol Chem 2000, 275:5512-5520.

30. Miyazaki J, Takaki S, Araki K, Tashiro F, Tominaga A, Takatsu K, Yamamura K: Expression vector system based on the chicken beta-actin promoter directs efficient production of interleukin-5. Gene 1989, 79:269-277.

31. Akagi $T$, Sasai $K$, Hanafusa $H$ : Refractory nature of normal human diploid fibroblasts with respect to oncogene-mediated transformation. Proc Natl Acad Sci USA 2003, 100:13567-13572.

32. Tabu K, Ohba $Y$, Suzuki T, Makino $Y$, Kimura T, Ohnishi A, Sakai M, Watanabe T, Tanaka S, Sawa H: Oligodendrocyte lineage transcription factor 2 inhibits the motility of a human glial tumor cell line by activating RhoA. Mol Cancer Res 2007, 5:1099-1109.

33. Tabu K, Ohnishi A, Sunden Y, Suzuki T, Tsuda M, Tanaka S, Sakai T, Nagashima K, Sawa H: A novel function of OLIG2 to suppress human glial tumor cell growth via p27Kip1 transactivation. J Cell Sci 2006, 119:1433-1441.
34. Scott GK, Chang CH, Erny KM, Xu F, Fredericks WJ, Rauscher FJ III, Thor AD, Benz CC: Ets regulation of the erbB2 promoter. Oncogene 2000, 19:6490-6502.

35. Kondo T, Setoguchi T, Taga T: Persistence of a small subpopulation of cancer stem-like cells in the C6 glioma cell line. Proc Natl Acad Sci USA 2004, 101:781-786

36. Puglisi MA, Saulnier N, Sgambato A, Rafanelli F, Barba M, Piscaglia AC, Boninsegna A, Giorda E, Carsetti R, Giuliante F, et al: Tumor-Initiating Cells in Colon Cancer and Liver Metastases: Biological and Molecular Characterization. Dig Liver Dis 2009, 41:S7.

37. Fisher RJ, Mavrothalassitis G, Kondoh A, Papas TS: High-affinity DNAprotein interactions of the cellular ETS1 protein: the determination of the ETS binding motif. Oncogene 1991, 6:2249-2254.

38. Wasylyk C, Maira SM, Sobieszczuk P, Wasylyk B: Reversion of Ras transformed cells by Ets transdominant mutants. Oncogene 1994, 9:3665-3673.

39. Wu C, Alman BA: Side population cells in human cancers. Cancer Lett 2008, 268:1-9.

40. Reynolds BA, Weiss S: Clonal and population analyses demonstrate that an EGF-responsive mammalian embryonic CNS precursor is a stem cell. Dev Biol 1996, 175:1-13

41. Horst D, Kriegl L, Engel J, Kirchner T, Jung A: CD133 expression is an independent prognostic marker for low survival in colorectal cancer. $\mathrm{Br} J$ Cancer 2008, 99:1285-1289.

42. Kojima M, Ishii G, Atsumi N, Fujii S, Saito N, Ochiai A: Immunohistochemical detection of CD133 expression in colorectal cancer: a clinicopathological study. Cancer Sci 2008, 99:1578-1583.

43. Song W, Li H, Tao K, Li R, Song Z, Zhao Q, Zhang F, Dou K: Expression and clinical significance of the stem cell marker CD133 in hepatocellular carcinoma. Int J Clin Pract 2008, 62:1212-1218.

44. Tong QS, Zheng LD, Tang ST, Ruan QL, Liu Y, Li SW, Jiang GS, Cai JB: Expression and clinical significance of stem cell marker CD133 in human neuroblastoma. World J Pediatr 2008, 4:58-62.

45. Rebetz J, Tian D, Persson A, Widegren B, Salford LG, Englund E, Gisselsson D, Fan X: Glial progenitor-like phenotype in low-grade glioma and enhanced CD133-expression and neuronal lineage differentiation potential in high-grade glioma. PLOS ONE 2008, 3:e1936.

46. Maeda S, Shinchi H, Kurahara H, Mataki Y, Maemura K, Sato M, Natsugoe S, Aikou T, Takao S: CD133 expression is correlated with lymph node metastasis and vascular endothelial growth factor- $C$ expression in pancreatic cancer. Br J Cancer 2008, 98:1389-1397.

47. Zeppernick F, Ahmadi R, Campos B, Dictus C, Helmke BM, Becker N, Lichter P, Unterberg A, Radlwimmer B, Herold-Mende CC: Stem cell marker CD133 affects clinical outcome in glioma patients. Clin Cancer Res 2008, 14:123-129.

48. Barker N, Ridgway RA, van Es $J H$, Wetering > van de $M$, Begthel $H$, Born van den M, Danenberg E, Clarke AR, Sansom OJ, Clevers H: Crypt stem cells as the cells-of-origin of intestinal cancer. Nature 2009, 457:608-611.

49. Velden van der AW, Thomas AA: The role of the $5^{\prime}$ untranslated region of an mRNA in translation regulation during development. Int J Biochem Cell Biol 1999, 31:87-106.

50. Esteller M: Cancer epigenomics: DNA methylomes and histonemodification maps. Nat Rev Genet 2007, 8:286-298.

51. Rajalingam K, Schreck R, Rapp UR, Albert S: Ras oncogenes and their downstream targets. Biochim Biophys Acta 2007, 1773:1177-1195.

52. Gotoh N: Control of stemness by fibroblast growth factor signaling in stem cells and cancer stem cells. Curr Stem Cell Res Ther 2009, 4:9-15.

53. Armstrong L, Hughes O, Yung S, Hyslop L, Stewart R, Wappler I, Peters H, Walter T, Stojkovic P, Evans J, et al: The role of PI3K/AKT, MAPK/ERK and NFkappabeta signalling in the maintenance of human embryonic stem cell pluripotency and viability highlighted by transcriptional profiling and functional analysis. Hum Mol Genet 2006, 15:1894-1913.

54. Sabnis AJ, Cheung LS, Dail M, Kang HC, Santaguida M, Hermiston ML, Passegue E, Shannon K, Braun BS: Oncogenic Kras initiates leukemia in hematopoietic stem cells. PLOS Biol 2009, 7:e59.

55. Guo X, Stratton L, Schrader JW: Expression of activated M-Ras in hemopoietic stem cells initiates leukemogenic transformation, immortalization and preferential generation of mast cells. Oncogene 2006, 25:4241-4244. 
56. Morel AP, Lievre M, Thomas C, Hinkal G, Ansieau S, Puisieux A: Generation of breast cancer stem cells through epithelial-mesenchymal transition. PLOS ONE 2008, 3:e2888.

57. Lee JS, Gil JE, Kim JH, Kim TK, Jin X, Oh SY, Sohn YW, Jeon HM, Park HJ, Park JW, et al: Brain cancer stem-like cell genesis from p53-deficient mouse astrocytes by oncogenic Ras. Biochem Biophys Res Commun 2008, 365:496-502.

58. Yu F, Yao H, Zhu P, Zhang X, Pan Q, Gong C, Huang Y, Hu X, Su F, Lieberman J, Song E: let-7 regulates self renewal and tumorigenicity of breast cancer cells. Cell 2007, 131:1109-1123.

59. Katayama K, Yoshioka S, Tsukahara S, Mitsuhashi J, Sugimoto Y: Inhibition of the mitogen-activated protein kinase pathway results in the downregulation of P-glycoprotein. Mol Cancer Ther 2007, 6:2092-2102.

doi:10.1186/1476-4598-9-39

Cite this article as: Tabu et al:: Analysis of an alternative human CD133 promoter reveals the implication of Ras/ERK pathway in tumor stemlike hallmarks. Molecular Cancer 2010 9:39.

\section{Submit your next manuscript to BioMed Central and take full advantage of:}

- Convenient online submission

- Thorough peer review

- No space constraints or color figure charges

- Immediate publication on acceptance

- Inclusion in PubMed, CAS, Scopus and Google Scholar

- Research which is freely available for redistribution

Submit your manuscript at www.biomedcentral.com/submit

() Biomed Central 